\title{
La defensa continental de América Latina en el pensamiento de Manuel Ugarte y Víctor R. Haya de la Torre (1900-1945)
}

\section{Eduardo Hodge Dupré*}

RESUMEN: El objetivo general del presente estudio es describir y analizar las ideas de defensa continental que Manuel Ugarte y Víctor R. Haya de la Torre profesaron durante la primera mitad del siglo xx. El propósito es plantear, por una parte, que hubo intelectuales latinoamericanos preocupados por los asuntos internacionales de la región y, por otra, que estas ideas fueron más allá de la integración y del antiimperialismo. Grosso modo, la hipótesis de este trabajo apunta a demostrar que ambos intelectuales pensaron que la defensa continental no iba a ser eficaz si no se lograba la integración latinoamericana ni tampoco si no se tenía claridad sobre quien atacaría, es decir, una noción real sobre el enemigo.

Palabras Clave: Pensamiento latinoamericano, Asuntos internacionales, Defensa continental.

ABSTRACT: The general objective of this paper is to describe and analyze the ideas of continental defense that Manuel Ugarte and Víctor R. Haya de la Torre professed during the first half of the twentieth century. The purpose is to identify, first, that Latinamerican intellectuals were concerned about international affairs in the region, and secondly, that these ideas were beyond the integration and antiimperialism. Roughly, the hypothesis of this study is to show that both intellectuals thought that continental defense would not be effective if the Latin American integration not was achieved nor was there clarity about who would attack, therefore, a real notion about the enemy.

KEY wORDS: Latinamerican thought, International affairs, Continental defense. 


\section{INTRODUCCIÓN}

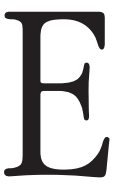

1 argentino Manuel Ugarte y el peruano Víctor Raúl Haya de la Torre fueron dos pensadores quienes durante la primera mitad del siglo XX escribieron sobre diversos asuntos de América Latina. Si bien pensaron sobre múltiples condicionantes que explicaban las razones de por qué nuestra región tenía un ritmo histórico un tanto más desfavorable que otras zonas más desarrolladas (Europa y Estados Unidos, por ejemplo), lo cierto es que ambos se centraron en tres variables que a sus juicios determinaban el acontecer latinoamericano: la integración latinoamericana, el imperialismo - principalmente estadounidense- y la defensa continental.

Los estudios sobre Ugarte y Haya de la Torre son numerosos (Norberto Galasso, Nieves Pinillos Iglesia, Ricardo Melgar Bao, Jussi Pakkasvirta, Claudio Maíz, Luis Alva Castro, Miguel Ángel Barrios, Daniel Iglesias); pero en ocasiones son escasos y a veces nulos los análisis que se centran en sus propuestas internacionales. Es más, en el plano académico, poco se ha escrito sobre pensamiento "internacional" latinoamericano (sólo sobresalen los trabajos de Daniel Guerra, Raúl Bernal Meza, Salvador Vásquez y Amado Cervo). Por esta última razón el presente trabajo busca ser un aporte a esta realidad, centrándose, principalmente, en la manera en que ambos latinoamericanos pensaron y concibieron la defensa continental. Grosso modo, es pertinente señalar que la defensa continental que el argentino y el peruano propusieron tenía un vínculo inherente con el resultado de la interacción entre la integración y el antiimperialismo. En otras palabras, la defensa continental no iba a ser funcional ni tampoco efectiva si los países latinoamericanos no se integraban, ni mucho menos si no se tenía claridad sobre quién atacaría (por esencia, la defensa tiene su razón de ser en la existencia de un agente que genera peligro).

Ahora, ¿qué se entenderá en este artículo por defensa continental? Para los efectos de este análisis, "defensa" será aquel instrumento destinado a "la conservación de la soberanía e integridad territorial de los estados de la región, al cuidado de sus recursos naturales para permitir un mayor bienestar del pueblo y a un grado suficiente de decisión en el concierto de competencias inter- 
bloques [...]". ${ }^{1}$ Ugarte y Haya de la Torre pensaron defensivamente en estos mismos términos: por una parte para proteger la soberanía y los intereses de los países de la región, y por otra, con el propósito de proponer un esquema que implicara la conformación de un bloque que fuera capaz de negociar con otros bloques. En ese sentido, la cita relaciona estrechamente las variables integración e imperialismo.

El objetivo de la defensa, por lo tanto, es mantener y asegurar la autonomía política, la seguridad y el bienestar de los pueblos. En efecto, las ideas de defensa se han pensado y formulado para conservar la integridad territorial de los estados y del equilibrio interregional. ${ }^{2}$ Las ideas defensivas de Ugarte y Haya de la Torre serán entendidas como un medio que le iba a permitir a América Latina conservar su autonomía, pese a los constantes intervencionismos estadounidenses; esta autonomía también implicaba proteger las áreas social y política, tan determinantes en el mantenimiento del bienestar del pueblo al que alude Koutoudjian. Respecto al segundo punto, la defensa también involucraba el concepto "equilibrio". Éste, en las ideas de ambos, sería aplicable tanto al terreno regional (entre naciones latinoamericanas) como también al plano "extra-americano", particularmente en el contexto de la Segunda Guerra Mundial, donde se esperó equilibrar la balanza a favor de Estados Unidos en desmedro de la Europa fascista.

Las siguientes líneas tienen como principal objetivo describir y analizar las nociones de "defensa continental" que Ugarte y Haya de la Torre elaboraron durante la primera mitad del siglo xx. Para ello, es necesario hacer una subdivisión en cuatro rubros que aclaren de manera concertada el tema: de quién defenderse y las razones de por qué defenderse, cómo defenderse, quiénes liderarán la defensa, el Estado como herramienta antiimperialista.

\section{DE QUIÉN DEFENDERSE Y LAS RAZONES DE POR QUÉ DEFENDERSE}

Manuel Ugarte y Víctor R. Haya de la Torre vivieron en un contexto en el cual las amenazas "extrarregionales" eran cotidianas. Durante las décadas de 1910, 1920

1 Adolfo Koutoudjian, "Pacto de defensa y seguridad del Cono Sur sudamericano", en Isabel Stanganelli, Seguridad y defensa en el Cono Sur, Buenos Aires, 2004 (Col. Cono Sur), p. 192.

2 Ibid., p. 193. 
y 1930, las intimidaciones provenían desde la nación más ascendente y poderosa del escenario internacional, Estados Unidos, cuyas pretensiones eran expandirse con la finalidad de alcanzar dos objetivos: a) satisfacer sus mercados internos por medio de la extracción de las materias primas de América Latina y b) expandir, al menos en el discurso, sus valores democráticos fundados en el "destino manifiesto". ${ }^{3}$ Pero estos objetivos muchas veces encontraron resistencias internas (un rechazo generalizado hacia todo lo yankee), lo que obligó al gobierno estadounidense a implementar medidas menos democráticas y, por cierto, más violentas.

La Primera Guerra Mundial (1914-1918) fue la expresión máxima del descontrol imperialista. ${ }^{4}$ La violencia y la ambición por captar nuevos mercados y poder internacional llevó a diversas naciones a enfrascarse en un conflicto de dimensiones multirregionales. Sin embargo, para Ugarte y Haya de la Torre hubo un hecho que ocurrió evidentemente más cerca de América Latina y que encendió la llama de la desconfianza respecto a la naturaleza misma del imperialismo, particularmente el de Estados Unidos: la lucha de liberación comandada por Sandino en 1927, cuyos desenlaces y dinámicas despertaron en ambos intelectuales una sensación de temor respecto a un estadounidismo capaz de operar de la misma manera en toda la región: marines entrenados luchando contra campesinos mal abastecidos; miles de muertos arrojados en la selva; gobierno central protegido por Estados Unidos; y empréstitos comerciales que afectaban la institucionalidad (por medio de fuga de dineros) y a la sociedad civil, esta última sometida por la explotación laboral del sistema capitalista. ${ }^{5}$

En un similar marco de vulnerabilidad, la idea de defenderse se justifica cabalmente. Ugarte señaló que en ciertos países existía "la opinión infantil de que el peligro no existe", para lo cual era necesario establecer un plan que destruyera - o asumiera - "la creencia desconsoladora de que es irremediable". 6 Pensar que

3 Cristián Guerrero et al., Breve historia de los Estados Unidos de América, Santiago, Universitaria, 1998.

4 Eric Hobsbawm, La era del imperio, Buenos Aires, Grijalbo/Crítica, 2001.

5 Salomón de la Selva, La guerra de Sandino o pueblo desnudo, Managua, Nueva Nicaragua, 1985.

6 Manuel Ugarte, "México, Nicaragua y Panamá", en el diario Crítica, Buenos Aires, 21 de febrero, 1927 [s. p.]. 
"no había vuelta atrás" era producto de una política exterior estadounidense que avanzaba sin tranzar, no sólo porque su sistema capitalista así lo demandaba o porque su cultura de exportar valores así lo proponía; también, porque su ascendente papel de potencia mundial le exigía establecer sus propias reglas del juego, sobre todo hacia las "desordenadas" e "infantiles" naciones del sur que podían, debido a su dispersidad y heterogeneidad, desestabilizar sus intenciones de establecer una democracia con ribetes mundiales (es menester señalar que la clase política, dirigente y económica de Estados Unidos consideró a los países latinoamericanos como bárbaros o como "niños" que necesitaban urgentemente madurar, por lo que alguien debía "enseñarles" - -ihe ahí la esencia del intervencionismo!)?

El "por qué" Estados Unidos intervenía en América Latina tiene, para Ugarte, una explicación sociocultural bastante significativa: mientras al norte vivían hombres y mujeres febriles, trabajadores, sistemáticos, ordenados y sobre todo integrados en una gran federación, al sur la situación era diametralmente distinta. Sin embargo, aquí "se agitan ochenta millones de hispanoamericanos de cultura y actitud desigual, divididos en veinte repúblicas que en muchos casos se ignoran o se combaten. Cada día que pasa registra una derrota de los del sur" " ${ }^{8}$ Las derrotas fueron aumentando, por una parte, a medida que el poder del norte también lo hacía, y por otra, a partir del divisionismo de los del sur. Acaso, inaciones dispersas hubiesen resistido eficientemente a los embates estadounidenses? ¿Uruguay, Bolivia, Paraguay, Guatemala tenían la capacidad unilateral de defenderse contra el imperialismo? Claramente no pero, con un programa potente en términos integracionistas, es probable que Estados Unidos ni siquiera hubiese querido mirar hacia el sur.

El temor y la incertidumbre eran aún mayores si se consideraba que el imperialismo no avisaba ni la hora ni el lugar para arremeter. Ugarte sostuvo que "nadie puede prever ante qué río o montaña se detendrá el avance de la nación

Véase Reginald Horsman, La raza y el destino manifiesto. Orígenes del anglosajonismo racial norteamericano, México, FCE, 1985; Ricardo Salvatore, Imágenes de un imperio. Estados Unidos y la forma de representación de América Latina, Buenos Aires, Sudamericana, 2006.

8 Manuel Ugarte, "La defensa latina", en el diario El País, Buenos Aires, 9 de noviembre, 1901 [s. p.]. 
que aspira a unificar el nuevo mundo bajo su bandera. Y la emancipación soñada, la resplandeciente hipótesis de la libertad de todas las colonias, va resultando un instrumento de dominación que precipita la pérdida de muchos". ${ }^{9}$ El autor reconoció el incremento de poder de Estados Unidos, el que para el Centenario de nuestras repúblicas ya manifestaba un evidente enfoque imperialista que tenía sus raíces en la experiencia de Cuba (1898), y que tras 1917 (entrada de Estados Unidos a la guerra), alcanzó niveles que se extendían hasta Europa. En efecto, para 1920 Estados Unidos tenía poder sin contrapesos y en zonas extracontinentales.

El temor que se producía frente al avance imperialista aumentaba cuando se reconocía que América Latina era bastante inferior a Estados Unidos. En este plano, Ugarte se planteó la siguiente pregunta: "¿qué son nuestras repúblicas de uno o de seis millones de habitantes ante la masa enorme de la nación más productora, más audaz y más progresiva que existe hoy en el mundo?". ${ }^{10}$ La debilidad de nuestra región se manifestaba indiscutiblemente en términos materiales, industriales, científicos o tecnológicos, pero también se expresaba a través de la incapacidad de nuestros países para generar un bloque capaz de contrarrestar los intereses del norte. En ese sentido, ambos pensadores reconocieron que las rencillas entre las naciones latinoamericanas eran el principal factor que explicaba la dispersión y/o desintegración; por su parte, esta última condición impedía que la región se posicionara de igual a igual con Estados Unidos, aumentando la incertidumbre y la perplejidad y, por lo tanto, la sensación de indefensión. Esto se agudizaba cuando había naciones que por ambición se aliaban a Estados Unidos, acrecentando la dependencia y proporcionando la entrada del imperialismo a la zona, lo cual arriesgaba su integridad y la de sus propios vecinos.

En este contexto, y pese a todas las rencillas existentes entre las regiones, el principal objetivo era defender la soberanía latinoamericana, por cuanto que el ataque imperialista pudo haber sido invasivo e intervencionista. Los norteamericanos no se iban a conformar sólo con llegar y establecer sus fuerzas militares,

9 Manuel Ugarte, "Causas y consecuencias de la Revolución Americana", en Mi Campaña bispanoamericana, Madrid, Cervantes, 1922.

${ }^{10}$ Ibid., p. 10. 
sino más bien iban a disponer de los destinos de nuestra región con el objeto de acaparar influencias y poder económico. Para lograr esto era necesario violentar a los estados y luego desconocer constituciones, reglas y mandatos políticos; suprimir parlamentos y sustituir sistemas judiciales. La resistencia social y política a estas imposiciones eran contundentes, por tanto, también lo iban a ser las represiones a estas manifestaciones (como la matanza que ordenó Leguía en Lima el 23 de mayo de 1923, cuando un grupo de jóvenes criticó su mandato). ${ }^{11}$

En esta misma línea, Haya de la Torre sostuvo que "nuestra primera tarea política es, consecuentemente, la tarea de defender nuestra soberanía. En esta obra de defensa ningún país aislado puede obtener la victoria. Si el peligro es común, económico, con proyecciones políticas, la defensa tiene que ser también común.."12 De estas líneas se desprenden y entrelazan varios conceptos: a) la prioridad de defenderse frente a cualquier ataque internacional por parte de Estados Unidos; b) ningún país de la región estaba a salvo de ser intervenido política, económica y militarmente, incluso aquellos que estaban más alejados de la potencia; c) la única posibilidad que los países de la región tenían para poder contener el avance, era hacerlo bajo el mismo paraguas. Es más, al ser minúsculas "gotas en un tremendo mar", a nuestros países no les quedaba otra que actuar integrados y así abandonar la dispersidad.

A mediados de la década de los años treinta, el foco de la preocupación de un posible ataque se centró en Europa. Esta situación se explicó dada la convergencia de dos sucesos: la "política del buen vecino" del presidente Roosevelt y el surgimiento del fascismo en Alemania, cuyo triunfo en el ámbito hemisférico preocupó a Haya de la Torre: "quedaremos nosotros a un paso de África, que será dominio del vencedor, y así seremos, Bélgicas y Holandas expandidas."13 El peligro se fundaba en que Alemania tenía colonias en África, justo en frente de Brasil, por lo que un triunfo de Deutsches Africa Korps (DAK) aceleraba la sensación de peligro para América Latina: iBrasil está a un paso de África! Por lo que la

\footnotetext{
11 Víctor Raúl Haya de la Torre, El antiimperialismo y el APRA, Santiago, Ediciones Nuestramérica, 1936, p. 24

12 Ibid., p. 74.

${ }^{13}$ Loc. cit.
} 
caída de Brasil aseguraba la caída del resto de las naciones. Esto era aún más complejo, por cuanto que el petróleo venezolano era un bien importante para las pretensiones bélicas del III Reich. Según Haya de la Torre, además del petróleo latinoamericano, Hitler mantuvo un gran interés por el Canal de Panamá, al que consideró clave para el comercio marítimo alemán y el control de los mares por la poderosa y ascendente armada nazi.

En el oeste, la violencia con la que actuaba el nazismo era visto y analizado con resquemor. En 1940 Estados Unidos aún no entraba a la guerra, pero Haya de la Torre se arriesgó y pronosticó que quedaba muy poco tiempo para que aquel evento se llevara a cabo. Las razones que pensó el peruano fueron tres: a) porque Estados Unidos no iba a aceptar contrapesos a su poder; $b$ ) porque sus preceptos democráticos difícilmente se iban a quedar pacientes al ver el ascenso de un autoritarismo que amenazaba al mundo por completo; y c) porque sus intereses económicos, operantes tras la Primera Guerra Mundial, aún estaban vigentes en Europa (recordemos que Hitler acusó al capitalismo de la debacle alemana). En ese contexto, y ya con un significativo enfoque "pro-nortemericano", Haya de la Torre propuso que, si el presidente Roosevelt decidía entrar a la guerra, América Latina debía formar un bloque de defensa interregional, cuyo objetivo sería proteger a las dos Américas de un posible triunfo fascista, en tanto que las riquezas y sociedades de ambas corrían peligro frente a las intenciones alemanas. ${ }^{14}$

No obstante lo anterior, y pese a la amabilidad de Roosevelt, Haya de la Torre desconfió de la política del "buen vecino", en tanto que "[...] el grave riesgo puede determinar una apresurada entrega al control norteamericano cuya buena vecindad puede variar cuando retornen al poder políticos de tendencia imperialista". ${ }^{15}$ Desde su mirada internacionalista, pensó que esta política sólo sería una cuestión momentánea, ya que al ser una política de gobierno y no de Estado no sería perpetua en el tiempo, y variaría según la ideología que se adjudicara el poder ejecutivo. Haya de la Torre pensaba que en el corto plazo serían los republicanos quienes asumirían el poder, los que indefectiblemente suprimi-

14 Víctor Raúl Haya de la Torre, La defensa continental [s. p. i.], 1941, p. 15.

15 Loc. cit. 
rían esta política de "buena vecindad" para asegurar al país de mantener la hegemonía mundial. Con esto no pretendo atribuirle una mirada más imperialista a uno u otro partido, pero es importante destacar que tanto para Ugarte como para Haya de la Torre los presidentes republicanos eran más proclives a mantener políticas exteriores de objetivos notoriamente más imperialistas; tampoco pensaron que los demócratas eran "santas palomas de la paz", o si no recordemos la conferencia de Ugarte en la Universidad de Columbia y sus críticas al supuesto idealismo del presidente W. Wilson.

Haya de la Torre propuso que, antes de aliarse a Estados Unidos, América Latina debía conformar un bloque de defensa intrarregional, cuyas propuestas se iban a alcanzar siempre y cuando se consolidara la integración latinoamericana. Con la finalidad de reducir el estado de permanente inseguridad frente a posibles conflictos de índole internacional, propuso que existía "una sola solución y de seguridad: la previa unión indoamericana [...] así haremos más fuerte la defensa en caso de agresión y porque así haremos más segura y garantiza[remos] la alianza con los Estados Unidos al juntarnos a ellos para la defensa común." ${ }^{16}$ Esto ratifica que pensó en una integración defensiva, es decir, un instrumento que le permitiría a la región negociar con Estados Unidos de "igual a igual", y no de "Estados Unidos" a "Estados Desunidos", lo cual no hacía sino obstaculizar la integridad de ambas regiones.

La defensa que pensaron Ugarte y Haya de la Torre fue razonada para proteger la integridad de América Latina y sus intereses. Éstos no eran necesariamente económicos, sino también sociales, culturales y políticos. El imperialismo, motivación directa para elaborar un pensamiento "defensivo", amenazó con usurpar riquezas, pero también con derrocar gobiernos, debilitar las estructuras públicas, destruir las diferentes clases sociales, e incluso asesinar si las circunstancias lo ameritaban. En ese contexto, el mayor peligro lo enfrentaba la soberanía nacional y social/popular, en tanto que los países quedaban atónitos y desesperanzados al ver la frialdad con la que actuaba Estados Unidos y sus compañías transnacionales. El estado de indefensión que producía la mano inter-

${ }^{16}$ Loc. cit. 
ventora del vecino del norte aumentaba en un contexto de desunión, por lo que ambos intelectuales propusieron como primera medida para erradicar ese estado, la integración de los pueblos: unidos serían capaces de defenderse contra el imperialismo, primero estadounidense, y luego fascista.

\section{CÓMO DEFENDERSE}

Las ideas de defensa que proyectaron Ugarte y Haya de la Torre fueron diferentes a las que proponen los estados actuales a través de sus ministerios del ramo, teóricos y personeros. Hoy en día los países compran armas cada vez más sofisticadas y profesionalizan a sus fuerzas armadas con mecanismos cada vez más tecnológicos, invirtiendo enormes sumas de dinero para tales propósitos. Incluso han decidido atacar militarmente por medio de métodos preventivos ("atacar antes que ataquen"). ${ }^{17}$ Sin embargo, ambos pensadores expusieron otros dispositivos, a pesar de tener en cuenta que el ataque podría alcanzar niveles extremos de belicismo. Entre estos instrumentos destacan dos: a) "armas eidéticas" que se traducen en la concientización - urgente-de materializar la integración, rechazar los capitales norteamericanos, incluso promover la industria nacional; y b) plataformas políticas como el APRA y plataformas comunicacionales como los periódicos, libros y conferencias, cuyos espacios fueron verdaderas trincheras para lanzar sus ideas y lograr protegerse de los ataques.

Al menos en una primera instancia, la defensa no debía ser bélica, ya que el imperialismo sólo atacaba militarmente cuando encontraba resistencia armada (como Nicaragua). En ese sentido, el primer instrumento que debían llevar sobre sus brazos los latinoamericanos era el "nacionalismo continental", el cual si bien se expresaba a través de formas beligerantes, lo cierto es que tanto el argentino como el peruano lo emplearon en otros asuntos que no eran precisamente el militar, como por ejemplo el industrial, económico y financiero. Ugarte fue un hombre que consideró y respetó a Argentina como su patria de origen, pero su pri-

${ }^{17}$ Un ejemplo contemporáneo de esta práctica es la guerra de Iraq y Afganistán, donde Estados Unidos ha atacado con el objetivo de defender su soberanía en el marco de la guerra contra el terrorismo. Véase Cristián Garay, La camaleónica naturaleza del conflicto posmoderno, Santiago, Biblioteca del Oficial, 2004. 
mera nación fue América Latina; esto ratifica que su visión internacional no era sobre la política exterior de su país, sino que el destino internacional de la región en su conjunto. ${ }^{18}$ Haya de la Torre coincidió con la interpretación de Ugarte al plantear que "es el nacionalismo el que nos enseña que ante el gran interés imperialista de los Estados Unidos del Norte, debemos oponer nosotros el gran interés de los pueblos que forman los Estados Unidos de Indoamérica, unidos por la suprema necesidad de defenderse". ${ }^{19}$ He ahí entonces una de las razones de por qué "nacionalizar" las riquezas naturales, el Canal de Panamá (internacionalizarlo en el ámbito latinoamericano), entre otros. El objetivo, en suma, era apropiarse de los instrumentos necesarios para comenzar a defenderse frente al poderío norteamericano. Al materializar estas propuestas, "dar a los latinoamericanos lo que es de ellos" no era sino una manera de resistir al capitalismo extranjero, que tradicionalmente había encontrado una sumisión material y espiritual por parte de las clases dirigentes y acomodadas, haciéndoles fácil la entrada y la usurpación de las materias primas que posteriormente industrializaban. En efecto, "interamericanizando Panamá y poseyendo todo lo que se nos quiere obligar a defender unidos, tendremos garantía viva contra cualquier posible imperialismo del Norte" ${ }^{20}$

Por su parte, Ugarte también examinó la variable nacionalista, y recalcó la "legítima defensa de mi nacionalidad. Los hombres que defienden, contra la inundación y contra el viento, su hogar, sus creencias y la cuna de sus hijos, acaban por hacerse simpáticos hasta a la misma tempestad", ${ }^{21}$ relacionaba así al imperialismo con fenómenos naturales que avasallaban sin respetar nada a su paso. Ugarte aludía al derecho autóctonamente latinoamericano, el cual debía ser respetado tanto o cuanto más que los deberes que Estados Unidos le exigía a la región en términos político-democráticos y económico-financieros (producción de mate-

18 Miguel Ángel Barrios, El latinoamericanismo en el pensamiento político de Manuel Ugarte, Buenos Aires, Biblos, 2007, pp. 72 y ss.

19 Haya de la Torre, El antiimperialismo y..., p. 88.

${ }^{20}$ Haya de la Torre, La defensa ..., p. 12.

${ }^{21}$ Manuel Ugarte, "Los pueblos del sur ante el imperialismo norteamericano", conferencia pronunciada en la Universidad de Columbia, Nueva York, 9 de julio, 1912. Incorporada luego por Ugarte a Mi campaña... 
rias primas); evidentemente apeló a lo ético para demostrar que América Latina debía ser incluso consultada, y no actuar sobre ella unilateralmente como lo hacía la Casa Blanca aliada a los "señores de la industria". Lo que él pensaba era que "los norteamericanos harían [lo mismo] en un caso análogo, si sintieran que peligraba su autonomía". ${ }^{22}$

Un segundo elemento fue la constitución de un pensamiento político internacional que definiera de manera cohesionada el procedimiento exacto de cómo defenderse. Una vez conformado, éste debía unir las fuerzas dispersas y luego unir los pueblos en torno al objetivo de la defensa. En ese contexto, Haya de la Torre puntualizó la cuestión en el aprendizaje que debían adquirir los latinoamericanos para luchar contra el enemigo - "omnipotente" según sus criterios- y cómo cumplir cabalmente las etapas de aquella lucha, ideológica al menos en un primer momento. Después de haber afirmado la unión de los pueblos y haber consolidado la defensa de la soberanía nacional/regional, el peruano propuso contactar, para lo que él llamó la "lucha final", "aliados que integren un gran movimiento nacionalista bajo las banderas del APRA" ${ }^{23}$ La Alianza que fundó sería la plataforma más idónea para comenzar la defensa, ya que una delegación en cada país de la región generaría redes capaces de contener el ataque imperialista. También, pensó reclutar a todos los hombres y mujeres provenientes de todas las clases sociales que consideraban que sus intereses estaban siendo amenazados por el imperialismo estadounidense.

En tercer lugar, Ugarte llamó la atención de los latinoamericanos en el plano cultural, donde el imperialismo también impactaba: ila cultura hispanoamericana estaba siendo amenazada por el anglosajonismo! Instó a sus coterráneos a confirmar su nacionalidad, sostuvo que para lograrlo era necesario que los hombres y mujeres defendieran su lengua y rompieran "con la debilidad que les ha llevado hasta ahora a inclinarse y a someterse a los idiomas extranjeros, desdeñando injustamente uno de sus más altos patrimonios". ${ }^{24}$ Desde su punto de vista, el idioma inglés se transformaba en un instrumento de dominación imperialista,

\footnotetext{
${ }^{22}$ Loc. cit.

${ }^{23}$ Haya de la Torre, El antiimperialismo y..., pp. 83 y 84 .

${ }^{24}$ Ugarte, "Los pueblos del sur ante... [s. p.].
} 
bastante presente en la región, por lo que recomendó consolidar el castellano como una medida nacionalista que facilitara la detención de la "frontera en movimiento" que Estados Unidos representaba para América Latina. Además, es importante señalar que el idioma fue interpretado por Ugarte como un mecanismo de control y, por cierto, de consolidación hegemónica.

Sin embargo, los instrumentos de defensa enfrentaban algunas dificultades en la manera de cómo protegerse, entre ellos estaban las comunicaciones, que por la falta de tecnologías eran lentas y altamente insuficientes. ¿Por qué insuficientes? ¿Acaso lo que había no bastaba? Si seguimos la lógica, el imperialismo era un fenómeno internacional que atacaría fugazmente a nuestra región, los medios de comunicación no alcanzaban a cumplir el objetivo de informar y solicitar auxilio, por lo que el imperialismo ganaba el terreno que los latinoamericanos perderían. En este sentido, y a modo de cuarto elemento, Ugarte expresó con preocupación que "el establecimiento de comunicaciones entre los diferentes países de la América Latina sería entonces la primera medida de defensa". ${ }^{25}$ Esto no sólo porque los medios de comunicación (ferrocarriles, telégrafos, navíos o correos) estaban en manos de capitales extranjeros, sino también porque un sistema comunicacional propiamente latinoamericano hubiese permitido a los pueblos estar informados, y así poder conocerse y ayudarse en situaciones críticas de acecho imperialista. ${ }^{26}$

En quinto lugar, se propone que, una vez unida y comunicada, América Latina no debía negociar con el imperialismo (en todas sus expresiones), ya que cualquier nexo político o económico con él, era arriesgarse a una usurpación de las riquezas naturales, a un sometimiento de la población y, por cierto, a intro-

25 Ugarte, "Causas y consecuencias... [s. p.].

${ }^{26}$ Ugarte, "La defensa latina..., p. 6. Señaló que un buen sistema de comunicaciones permitiría que "las relaciones se harían cada vez más estrechas. Las fronteras perderán su carácter de murallas chinas y los diferentes pueblos puestos en contacto irán olvidando sus prevenciones para aprender a conocerse $[. .$.$] se establecerá un ir y volver de intereses y simpatías. Y de ese intercambio$ de gentes e ideas, de las comarcas comerciales que hacen nacer las líneas de comunicación, de la relativa comunidad de costumbres y de propósitos, nacerá al cabo de poco tiempo la necesidad de estrechar vínculos y precipitará acercamientos, hasta confundirnos en el porvenir como lo sostuvimos en el pasado". 
misiones en los aparatos públicos. En ese sentido, Haya de la Torre señaló que "el APRA sostiene la utilización táctica de todos los medios de defensa antiimperialista que puedan descubrirse en el conflicto de los capitalismos, usándolos como avanzadas, pero sin caer jamás en convenios claudicantes". ${ }^{27}$ Cualquier tipo de pacto con el imperialismo conllevaba a perder la autonomía y a caer en una dependencia estructural. Si se piensa en el imperialismo norteamericano es necesario considerar que Estados Unidos no se sometería jamás al arbitrio de otra nación, ni mucho menos cumpliría compromisos que los países latinoamericanos -débiles institucionalmente, indígenas, corruptos y perezosos-le obligaran. Acaso, ¿cómo el país más democrático y poderoso del orbe se iba a supeditar a estos países que genética, social y económicamente le eran inferiores? En suma, era impensable que el imperialismo dejara de serlo sólo por convenir en algunos aspectos con América Latina; el imperialismo no decaería, sino que se consolidaría y extendería porque así lo requerían los nuevos tiempos, en los que emergían potencias igualmente imperialistas que competirían con Estados Unidos sea cual fuere el precio.

En sexto lugar, tenemos otro método de defensa pensado por ambos intelectuales: asociar a nuestra región con otra potencia que ejerciera un contrapeso mayor a las intenciones de Estados Unidos. Al menos hasta el final de la Primera Guerra Mundial, Ugarte pensó en "el contrapeso que los intereses europeos deben ejercer". Países como Francia, Inglaterra, Alemania e Italia, luego de haber empleado "en las repúblicas del sur grandes capitales y han establecido inmensas corrientes de intercambio o de emigración", ${ }^{28}$ estaban capacitadas para contrarrestar el poder estadounidense. La idea radicaba en que si Estados Unidos decidía atacar o poner a prueba su hegemonía sobre América Latina de manera económica, política y militar, simultáneamente se hubiese encontrado frente a frente con las fuerzas de otra nación, más organizada y con ciertas tradiciones asociadas al poder. Éste, por cierto, era un procedimiento que consideraba como primera alternativa un mecanismo de contención material más que ideológico,

\footnotetext{
27 Haya de la Torre, El antiimperialismo y..., p. 83.

28 Ugarte, "La defensa... [s. p.].
} 
y más pacífico que militar (al menos antes de que el imperialismo ejerciera fuerza, a través de medios bélicos). Los capitalistas europeos no harían sino preservar sus intereses de la avalancha norteamericana, produciendo lo que Ugarte estimó como una estrategia de defensa positiva: "este choque de ambiciones es la mejor garantía para los latinos de América". ${ }^{29}$ En ese sentido, el argentino pensó que España podría haber desempeñado un papel preponderante en este proceso, más aún si se tenían en mente los lazos sanguíneos que existían entre América Latina y esta nación; esto, de una manera u otra, aumentaba las posibilidades de simpatía y, por tanto, de ayuda mutua.

Era común en Ugarte encontrar ideas más afines a las variables sociales y políticas. No obstante, y directamente relacionado al sexto punto, propuso un séptimo elemento cuya finalidad era proteger a América Latina a partir de alianzas netamente económicas con otras potencias, cuyos efectos impactarían directamente en el sistema financiero estadounidense, causando, de paso, una desestabilidad al interior de Estados Unidos que le impidiera inmiscuirse en el sur. La potencia del norte poseía un sistema financiero centralizado, por lo que una contención o un choque con otros intereses económicos podrían haber significado el colapso general del país. La visión de Ugarte fue mucho más allá, al pensar que una crisis no sólo le afectaría en términos económicos, sino que también produciría conflictos sociales que irían expandiéndose a todas las clases, incluso la dirigente. En consecuencia, una crisis de esta magnitud tendría un efecto casi fulminante en las esferas políticas, obligando al gobierno a actuar en el escenario interno y abandonar, o al menos disminuir, sus intervenciones externas, por lo que América Latina respiraría del imperialismo un tiempo que le permitiera reedificarse y así comenzar procesos tan urgentes como la integración latinoamericana.

En octavo lugar, y en sincronía con el eventual colapso financiero-social de Estados Unidos, los pueblos latinoamericanos debían comenzar un proceso de reformas políticas internas. Según Ugarte, América Latina no podía defenderse del imperialismo norteamericano con gobiernos locales incapaces de pensar más

${ }^{29}$ Loc. cit. 
allá de sus propias fronteras, o que estuvieran "a la altura del pueblo por su inteligencia y por su voluntad para el sacrificio". ${ }^{30}$ Insistía que los pueblos del sur aún no sentían la mano dura del capitalismo norteamericano, Ugarte pensó por tanto que "estamos todavía a tiempo de evitar muchas cosas", por lo que ganar tiempo en esta lucha era una ventaja que no se debía desaprovechar. En ese sentido, y beneficiándose de la coyuntura, el argentino recomendó no "intervenir en el conflicto sino cambiar de política interior", estableciendo la fortificación de la democracia y la participación de las clases populares en los asuntos políticos, en tanto son éstos, y no las oligarquías, los actores más propicios para enfrentar al imperialismo (ilas oligarquías eran, para el argentino, las principales aliadas de Estados Unidos!).

Se ha sostenido desde el principio que la defensa que pensaron Ugarte y Haya de la Torre tuvo un enfoque de no beligerancia, al menos originalmente, ya que dependía de cómo operaría el imperialismo norteamericano; si caía con fuerza como lo hizo en Nicaragua, el discurso pacífico daba paso a la acción bélica. Por ello ambos pensadores no descartaron la alternativa de utilizar instrumentos agresivos para contener una invasión militar. Por esta razón creo que, en noveno lugar, se estructura un mecanismo cuyas dimensiones son de "última instancia". Ugarte sí fue partidario de utilizar las armas y los ejércitos; es más, una de las razones de por qué abandonó el Partido Socialista argentino fue porque discrepó fuertemente con sus correligionarios socialistas respecto a la existencia de los ejércitos nacionales. Para los socialistas, los ejércitos no eran sino los instrumentos que las oligarquías utilizaban para reprimir a las masas proletarias, así como de contención de los países imperialistas sobre las colonias. Sin embargo, Ugarte entendió que los ejércitos nacionales no eran sino los medios de defensa de las soberanías nacionales en los momentos en que el imperialismo se dejaba caer con fuerza.

Como última opción, Ugarte pensó que los ejércitos eran necesarios para asegurar la contención, pero también para resguardar las riquezas naturales, el desarrollo humano y material de las naciones latinoamericanas. Por ejemplo,

${ }^{30}$ Ugarte, "México, Nicaragua... [s. p.]. 
cuando alabó el progreso estadounidense, lo hizo en función de su capacidad bélica, la cual le permitió una expansión rápida y sin amenazas, como también posicionarse como una nación gigante y robusta. En ese sentido, las dos guerras mundiales situaron a Estados Unidos como una potencia internacional, tanto en el ámbito doctrinario como en la capacidad de fuego. Al considerar su poderío militar, Ugarte no excluyó la posibilidad que este país atacara militarmente, por lo que la respuesta de los latinoamericanos no debía ser sino militar. Respecto al ejército, sostuvo que de su "desarrollo y enaltecimiento soy partidario [...]", y a propósito de su funcionalidad, pensó que, "así como no se concibe un banco sin cerraduras, no puede existir un país próspero sin una fuerza respetada y honrada por todos, que garantice su desarrollo". ${ }^{31}$ En consecuencia, los ejércitos que tuvo en mente no eran para que los países latinoamericanos se destruyeran mutuamente (un temor latente en el pensamiento de éstos y de otros también); eran más bien, para que contuvieran el avance del imperialismo norteamericano revestido en su forma militar.

La razón de por qué Ugarte entendió la guerra como la instancia última no sólo respondió a que el imperialismo no iba a atacar sin una provocación previa, sino también porque América Latina no tenía los medios suficientes para librar un conflicto de aquella amplitud; una situación así, le traería más desgracias que beneficios. Para evitar que la guerra impactara de manera negativa en la región, y así descartarla como un procedimiento para nuestros países, Ugarte pensó que la creación de centros de defensa en varios países latinoamericanos sería una alternativa viable (para Haya de la Torre, estos centros tenían espacio en las células apristas). Estos centros tendrían la capacidad de generar redes de ayuda mutua, de modo que si el imperialismo deseaba atacar, éstos se coordinarían y constituirían una compleja conexión de resistencia principalmente pacífica (ya que no los pensaba armados). La instauración de estos centros sería menos costosa que los ejércitos, como también menos provocativa a los intereses norteamericanos. La intención de Ugarte era recorrer cada uno de los países llevando esta idea como baluarte, con el propósito de ir "al foco mismo de don[de] parte

31 Manuel Ugarte, "Manifiesto", en Manuel Ugarte y el Partido Socialista. Documentos recopilados por un argentino, Buenos Aires, Hispano-Argentina, 1913 [s. p.]. 
la amenaza, no en son de guerra, sino serenamente, para decir: 'Aquí la cuestión, examinémosla"'.32

En suma, en las ideas y propuestas defensivas de Ugarte y Haya de la Torre predominó la visión pacifista antes que la belicista. Sin embargo, al menos más en el primero que en el segundo, no se descartó la posibilidad de practicar una defensa continental por medio de instrumentos bélicos. Al prevalecer una sobre la otra, el propósito de estos pensadores fue aclarar que las alternativas de ataque no eran planteamientos retóricos, sino reales y latentes. En ese sentido, se pensaron opciones reservadas a fortalecer la imagen de América Latina, concientizando que lo "propio" era un instrumento válido y eficaz en la lucha contra el imperialismo. Sobreponer lo local a lo universal fue una idea permanente en las ideas sobre defensa, ya que para consolidar la integración —entendida como el objetivo principal de estos autores-, la región debía estar atenta porque un ataque pondría fin a toda la cultura latinoamericana.

\section{QUIÉNES LIDERARÁN LA DEFENSA}

Para Ugarte y Haya de la Torre, los únicos que podían llevar a cabo la defensa continental eran los latinoamericanos quienes, a través de la integración regional, debían estar preparados - al menos ideológicamente- para contener el avance de la "frontera en movimiento" (término utilizado para referirse a Estados Unidos). Haya de la Torre pensó que la plataforma más propicia para lograr este propósito era la APRA, mientras que Ugarte propuso que la resistencia emanara desde las bases sociales, las cuales sufrían fuertemente los embates del imperialismo. Ambos excluyeron de este proceso a las clases dirigentes, a las que consideraron las primeras, únicas y más importantes aliadas del imperialismo; por esta razón se preocuparon por instruir en este ámbito de la resistencia a las clases trabajadoras y obreras, formando asociaciones intelectuales que problematizaran y expusieran los proyectos y programas de defensa, para que después estos grupos resistieran sin cuartel contra el imperialismo. En efecto, estamos

32 Ugarte, "Los pueblos del sur ante... [s. p.]. 
frente a una suerte de "centro de difusión e información" para aquellos sectores menos conocedores de la realidad internacional.

Sin embargo, la resistencia no debía ser proyectada por cualquier intelectual, en tanto que muchos sólo interactuaban dentro de los marcos de lo metafórico o lo romántico. Por su parte, Ugarte difundió la idea de defender las autonomías de los países más afectados por el imperialismo, mientras los gobernantes discutían intrigas personales y los filósofos "exponen teorías abstractas, ajenos a la inminencia de la catástrofe". ${ }^{33}$ En este sentido, lo que el argentino intentó explicar fue que la defensa continental debía contar con personas capaces de distinguir la realidad de la ficción, y asumir que las intervenciones extranjeras - particularmente la estadounidense - eran la principal causa de las enfermedades de América Latina, impactando de igual manera todas sus estructuras políticas, económicas y culturales. Por esta razón era necesario contar con un grupo de personas que conociera nuestra región e idealmente conociera, al menos en parte, la realidad norteamericana (como la estrategia de "conocer al enemigo para saber cómo reacciona").

Los intelectuales que estaban conscientes que el imperialismo era una política internacional que perturbaba los destinos de América Latina tenían una tarea fundamental en el proceso de defensa continental: promover la idea de que los mecanismos de resguardo ya señalados sí eran efectivos en el proceso de contención y protección. Para Haya de la Torre, "la formación de una conciencia antiimperialista en nuestros pueblos es, pues, el primer paso hacia su defensa integral". ${ }^{34}$ Esa conciencia era, en una primera instancia, económica y política, pero también representaba aspectos sociales y culturales (esto último más presente en el argentino que en el peruano). El objetivo era fomentar el nacionalismo económico como un instrumento funcional para conservar la libertad, pero no desde el mundo académico ni popular, sino político. En ese sentido, planteó que "sólo un partido político nacional indoamericano podría formar

33 Manuel Ugarte, "Nacionalismo y renovación", en El dolor de escribir, Madrid, 25 de mayo, 1932 [s. p.].

${ }^{34}$ Haya de la Torre, El antiimperialismo y... [s. p.]. 
y conducir esa conciencia. Es ella la que nos guardaría de caer arrollados en una conflagración imperialista".,35

La conciencia que impulsó Ugarte tuvo connotaciones evidentemente radicales. Él pensó que la intransigencia debía moverse desde abajo y de manera transversal, al considerar incluso el rechazo hacia los productos rotulados como "made in USA". El objetivo era resistir todo tipo de influencias, utilidades o suministros provenientes desde Estados Unidos. Esta postura ya era un indicador que la obstinación hacia lo norteamericano se estaba arraigando en la sociedad, posicionándose de forma rápida como una alternativa legítima en las prácticas de contención antiimperialistas. A propósito de los efectos que producía el capital extranjero en la región, y en particular sobre las sociedades latinoamericanas, Ugarte señaló que se estaba "creando entre la América Latina y la América anglosajona un ambiente de antagonismo y de repulsión [.. . ] contra lo que nos sublevamos es contra la tendencia a tratarnos como raza subalterna y conquistable" ${ }^{36}$ La estrategia de resistencia ugartiana no tenía otra finalidad que construir barreras internas al imperialismo; lo que esperaba el argentino era que los latinoamericanos no consumieran los productos extranjeros y que rechazaran la cultura "invasora", lo que automáticamente iba a generar trabas internas al paso del capital externo, impidiendo así que éste proliferara (y de paso impactara tal cual lo venía haciendo desde hacía decenios atrás).

No obstante lo anterior, el trabajo de concientizar a la población en materias antiimperialistas y defensivas no iba a ser un trabajo fácil. La dispersión, el desconocimiento, el caudillismo nacionalista y los revanchismos vecinales, impedirían formar una "conciencia latinoamericana", en tanto que cada país estaba ensimismado en sus propias realidades. ${ }^{37}$ Esto, en suma, no sólo iba a perjudicar la integración de los países, sino también los procedimientos de defensa continental: era una ardua tarea convencer a todos los países de llevar a cabo sus programas defensivos de una manera unísona, lesionando toda posibilidad de protección

35 Loc. cit.

${ }^{36}$ Ugarte, "Los pueblos del sur ante... [s. p.].

37 En "El lobo y los corderos", Ugarte sostuvo la "incapacidad de la clase política en el proceso de integración. Para ello, se remonta a los tiempos de la independencia: "[... ] porque a los grandes 
mutua. Haya de la Torre, pese a esta realidad, señaló que "el plan defensivo antiimperialista de nuestros pueblos debe basarse en la canalización y sistematización de todas las fuerzas dispersas que presienten o sienten, intuyen o comprenden el gran problema y se aprestan a afrontarlo sin coordinación ni método" ${ }^{38} \mathrm{El}$ peruano propuso organizar y sujetar todas esas fuerzas sociales con la finalidad de dirigirlas hacia un campo de acción renovador y constructivo, y enseñarles que la enemistad no conducía a nada más que a la animadversión y por cierto dispersión, ambos elementos claves para entender el estado de indefensión.

En su recorrido, el imperialismo no discriminaba entre las clases sociales locales, sino por el contrario, de una u otra manera, todas sentían el peso de su avance. Pero pese a dicha transversalidad, no todas estaban en condiciones de participar en la defensa continental; como ya se ha mencionado, hubo sectores de la sociedad latinoamericana que mantuvieron lazos muy estrechos con el imperialismo, lo cual cobró vida a través de negocios, pactos y protectorados, entre otros. Los únicos que debían combatirle y que, por cierto, tenían las herramientas propicias para aquella labor, eran los sectores más pobres; aquella masa de personas explotadas por el capital extranjero y subordinadas al poder oligárquico; ihe aquí el grupo de personas que Ugarte y Haya de la Torre convocaron para las tareas defensivas! En sus palabras, el peruano señaló que la defensa continental se "debe arraigar en las grandes masas nacionales." 39

Quienes lideraran el proceso de defensa debían ser los hombres y mujeres de América Latina, pues eran los únicos que verdaderamente conocían cada uno de los requerimientos de la región; para ambos intelectuales ni los comunistas soviéticos ni los liberales norteamericanos tenían derecho a intervenir en nuestros asuntos internos. Por este motivo era urgente concientizar y doctrinar a los latinoamericanos en alguna actividad asociada a la defensa continental, de

patriotas de la independencia que tendieron siempre a la confederación, habían sucedido los caudillos o los gobernantes timoratos o ambiciosos que, después de multiplicar durante una generación las subdivisiones para crear feudos o jerarquías, se debatían, prisioneros de los errores pasados, en el sálvese quien pueda de una muchedumbre sin solidaridad."

${ }^{38}$ Haya de la Torre, El antiimperialismo y..., p. 165.

39 Haya de la Torre, La defensa..., p. 51. 
modo tal que aprendieran ciertas técnicas y procedimientos atingentes a la resistencia. Defenderse no era una tarea fácil; más bien, se requería de una táctica compleja que no aseguraba el triunfo. El imperialismo constituía una compleja red de sistemas, ideas y métodos que no se podían contener sólo con críticas, discursos y metáforas. Con la finalidad de formar una contención más efectiva, era necesario persuadir a las personas sobre cuán riesgoso era permitir y facilitar la embestida imperialista. Esto presenta una manera distinta a la lucha antiimperialista convencional, en tanto que la resistencia comenzaba desde dentro con actitudes pacíficas, pero sin excluir la alternativa de lucha militar.

\section{CONCLUSIONES}

Las ideas internacional-defensivas de Ugarte y Haya de la Torre fueron bastante claras: el objetivo era proteger los intereses, recursos y sociedades latinoamericanas del imperialismo estadounidense. También, se propusieron contener al imperialismo porque lo consideraban el principal causante de los problemas de la región. Por lo tanto, si se deseaba continuar avanzando en la senda del progreso, era obligatorio ponerles límites al intervencionismo político y a la expansión de capitales provenientes de Estados Unidos en América Latina.

Los encargados de proteger la región serían los latinoamericanos, quienes a su vez, eran los únicos afectados e impactados por las embestidas políticas y financieras de la política imperialista del gobierno de Estados Unidos. No obstante, no se descartó la posibilidad de recurrir a otras instancias que complementaran tal procedimiento, como por ejemplo aprovechar los lazos culturales con Europa para así crear una suerte de equilibrio de poder que contrarrestara los intereses norteamericanos. Estas ideas tuvieron un giro evidente tras la Primera Guerra, en tanto que, en vez de debilitarse, Estados Unidos adquirió más fuerza.

La defensa que idearon era eminentemente pacífica, nunca invitaron a atacar a Estados Unidos a modo de protección (una suerte de "atacar por si acaso"). No propusieron resistir el imperialismo y sus capitales a punta de lanza ni fuego, sino más bien a partir de una oposición hacia los servicios de empresas estadounidenses, principalmente en el área del transporte y las comunicaciones. Esto, algún día, causaría pérdidas financieras, obligando a las empresas a regresar a su país de 
origen o simplemente buscar otras colonias. Sin embargo, si el imperialismo quería atacar, la resistencia armada se constituía en una alternativa viable.

Ugarte y Haya de la Torre colocaron el problema de la defensa continental como un tema importante dentro de las ideas internacionales latinoamericanas. Pensaron que la lucha contra el imperialismo era una lucha destinada a conservar la integridad y comenzar la integración (la referencia de un "otro" "diferente" pudo haber provocado la cohesión de estos "otros"), como también la autonomía, siendo esta última un factor relevante para entender el estado de vulnerabilidad frente a las intenciones políticas y comerciales de Estados Unidos.

Otro componente importante a destacar fue la trascendencia entregada al Estado, el que debía ser un instrumento para la defensa contra las amenazas internacionales. He aquí entonces, una fuente inspiradora para muchos intelectuales latinoamericanos de los años posteriores, que reivindicaron el papel del Estado en los asuntos internacionales como motor de acercamiento y diplomacia. Esta macro-estructura era la encargada de detener el avance del imperialismo, como también de reconocerlo como un problema común para América Latina (por cierto, también para idear estrategias destinadas a contenerlo).

Ambos elaboraron un concepto de defensa que no ha sido considerado por los estudios actuales. Al menos buena parte de la bibliografía consultada para este trabajo y otros, no citan ni aluden a la defensa que Ugarte y Haya de la Torre propusieron. La razones de ello podrían ser: a) las necesidades que esgrimieron de por qué defenderse no implicaron esencialmente la existencia de un "otro" armado (en otras palabras, no fue su "razón de ser"), requisito indispensable para su teorización; $b$ ) quizá quienes trabajan estos temas desconocen que durante las décadas de 1910, 1920 y 1930 existieron hombres públicos que, sin ser militares ni estadistas, se preocuparon por trabajar e idear conceptos asociados a la defensa continental. Por esta razón este análisis intentó demostrar que sí hubo latinoamericanos que se esforzaron por construir un paradigma internacional destinado a proteger a América Latina de un ataque internacional.

En suma, la defensa continental era un proyecto ideado por Ugarte y Haya de la Torre designado para resguardar los intereses de América Latina, en tanto que éstos estaban en peligro frente a la arremetida estadounidense. Por esto, la defensa 
debía constituirse como una tarea integracionista de mayor proporción, ya que unidos los países latinoamericanos podrían hacer mayor contrapeso a las intervenciones norteamericanas. Por lo tanto, la integración latinoamericana y el antiimperialismo se conectaban de mejor manera con la presencia de las ideas defensivas.

Recibido: 31 de agosto, 2010.

Aceptado: 11 de enero, 2011.

BibLIOGRAFÍA

Barrios, Miguel Ángel, El latinoamericanismo en el pensamiento político de Manuel Ugarte, Buenos Aires, Biblos, 2007.

Bernal MeZa, Raúl, América Latina en el mundo. El pensamiento latinoamericano y la teoría de las Relaciones Internacionales, Buenos Aires, Grupo Editor Latinoamericano, 2005.

CASTRo AlVA, Luis, El sueño del libertador. Haya de la Torre y la unidad de América. Antología, Lima, Fondo Editorial del Congreso de Perú, 2004.

CERVO, AMADO, Inserçâo Internacional. Formaçâo dos conceitos brasileiros, São Paulo, Saraiva, 2007.

Galasso, Norberto, Manuel Ugarte, Buenos Aires, EubEDA, 1970. , Manuel Ugarte y la lucha por la unidad latinoamericana, Buenos Aires, Corregidor, 2001.

GuERRA, DANiel, El pensamiento internacional de Bolivar, Caracas, Ragón, 1955. Guerrero, Cristí́n, Breve historia de los Estados Unidos de América, Santiago, Universitaria, 1998.

Haya de la Torre, Víctor R., El antiimperialismo y el apra, Santiago, Chile, Nuestramérica, 1936. , La defensa continental [s. 1.], [s. e.], 1941. 
Hobsbawm, Eric, La era del imperio, Buenos Aires, Grijalbo/Crítica, 2001.

Horsman, Reginald, La raza y el destino manifiesto. Orígenes del anglosajonismo racial norteamericano, México, FCE, 1985.

IgLESIAS, DANIEL, Articulaciones relacionales y redes transnacionales: acercamiento crítico para una nueva historiografía del aprismo continental. En http://nuevomundo.revues.org/index8602.html.

Koutoudjian, Adolfo, "Pacto de defensa y seguridad del Cono Sur sudamericano", en Isabel Stanganelli, Seguridad y defensa en el Cono Sur, Buenos Aires, 2004 (Col. Cono Sur).

Maíz, Claudio, Imperialismo y cultura de la resistencia. Los ensayos de Manuel Ugarte, Buenos Aires, Ediciones del Corredor Austral, 2003.

Melgar BaO, Ricardo, "Militancia aprista en el Caribe: la sección cubana", en Cuadernos Americanos, núm. 37, México, unam, 1993.

PAKKASVIRTA, Jussi, "Haya de la Torre en Centroamérica (1928): iprimera y última fase del aprismo internacional?", en Congreso Centroamericano de Historia, San Salvador, 2000. En http://www.helsinki.fi.

Peralta Rivera, Germán, La ética del joven Haya, Trujillo, Municipalidad Provincial de Trujillo, 1995.

PInillos, Nieves, Manuel Ugarte, Madrid, Ediciones de Cultura Hispánica, 1989. SALVATORE, RICARDO, Imágenes de un imperio. Estados Unidos y la forma de representación de América Latina, Buenos Aires, Sudamericana, 2006.

Selva, Salomón, La guerra de Sandino o pueblo desnudo, Managua, Nueva Nicaragua, 1985.

UgarTe, Manuel, "Causas y consecuencias de la Revolución Americana", en Mi Campaña hispanoamericana, Madrid, Cervantes, 1910.

, "El lobo y los corderos", en El destino de un continente, Madrid, Mundo Latino, 1923.

, "La defensa latina", en El País, Buenos Aires, 9 de noviembre, 1901.

, "Los pueblos del sur ante el imperialismo norteamericano", conferencia pronunciada en la Universidad de Columbia, Nueva York, 9 de julio, 1912, en Mi campaña bispanoamericana, Madrid, Cervantes, 1912. 
,"Manifiesto", en Manuel Ugarte y el Partido Socialista. Documentos recopilados por un argentino, Buenos Aires, Hispano-Argentina, 1913.

, "México, Nicaragua y Panamá", en el diario Crítica, Buenos Aires, 21 de febrero, 1927.

, "Nacionalismo y renovación", en El dolor de escribir, Madrid, 25 de mayo, 1932.

VázQuez, Salvador, El pensamiento internacional de Octavio Paz, Puebla, Universidad de Puebla, 2006. 